\title{
Uma análise da percepção acadêmica de Ciências Contábeis sobre o estágio supervisionado frente a inserção mercadológica
}

\section{An analysis of the academic perception of Accounting Sciences on the supervised stage in front of the market insertion}

\section{Recebimento: 01/11/2020 - Aceite: 12/01/2021 - Publicação: 01/02/2021 \\ Processo de Avaliação: Double Blind Review}

Felipe Borges Santana ${ }^{1}$

Mestrando em Administração pela Universidade Federal de Sergipe (UFS)

feelip-borges@hotmail.com

Esdras Antunes do Nascimento

Doutorando em Administração pela Universidade Federal de Minas Gerais (UFMG)

eanascimento7@gmail.com

Eúde do Amor Cornélio

Mestre em Administração Universidade Federal de Sergipe (UFS)

eudec@hotmail.com

Jefersson David Araujo Sales

Doutor em Administração Universidade Federal de Pernambuco (UFPE)

Professor do Departamento de Administração da Universidade Federal de Sergipe (UFS)

profsales@hotmail.com

\section{RESUMO}

Esse estudo se propôs a criar uma análise sobre o estágio supervisionado do curso de ciências contábeis como ferramenta para a inserção mercadológica. A sua fundamentação teórica se divide em duas seções, de forma linear e metodologicamente dedutiva, a pesquisa segue do geral ao particular abordando sobre a importância da satisfação do concludente quanto a sua formação, o processo formativo do acadêmico de contabilidade, com duas subseções a relação da teoria/prática e por fim, o estágio supervisionado e sua importância formativa. O objetivo geral desse estudo foi comparar os acadêmicos concludentes que estão imersos no mercado de trabalho e os que não estão sobre a importância do estágio

\footnotetext{
${ }^{1}$ Autor para correspondência: Universidade Federal de Sergipe (UFS): Av. Marechal Rondon, s/n - Jardim Rosa Elze, São Cristóvão - SE, 49100-000 - Brasil.
} 
supervisionado no curso de ciências contábeis. A metodologia empregada segue os preceitos de uma pesquisa experimental, com abordagem qualitativa e na coleta dos dados utilizou a técnica de questionários estruturados. Com esse estudo, os resultados alcançados respondem que há uma compreensão quanto ao descompasso da prática contábil acadêmica com a prática contábil mercadológica, bem como um entendimento de que o currículo de ciências contábeis precisa passar por uma atualização de conteúdos. No entanto, a maioria dos alunos concludentes não observa a ausência de temas relevantes sobre a contabilidade tratados no estágio, mas evidenciam que o currículo de ciências contábeis da IES atende parcialmente as suas necessidades de formação.

Palavras-chave: estágio supervisionado, formação profissional contábil, inserção mercadológica, relação teoria-prática, qualidade no ensino superior.

\section{ABSTRACT}

This study set out to create an analysis of the supervised internship in the accounting science course as a tool for market insertion. Its theoretical foundation is divided into two sections, in a linear and methodologically deductive way, the research follows from the general to the private, addressing the importance of concluding the student's satisfaction with his / her education, the accounting academic's training process, with two subsections the relationship theory / practice and finally, the supervised internship and its formative importance. The general objective of this study was to compare the concluding academics who are immersed in the job market and those who are not on the importance of the supervised internship in the accounting science course. The methodology used follows the precepts of an experimental research, with a qualitative approach and in the data collection, it used the technique of structured questionnaires. With this study, the results achieved respond that there is an understanding of the gap between academic accounting practice and marketing accounting practice, as well as an understanding that the accounting science curriculum needs to undergo a content update. However, the majority of concluding students do not observe the absence of relevant topics on accounting dealt with in the internship, but show that the IES accounting science curriculum partially meets their training needs. 
Keywords: Supervised internship; professional accounting training; market insertion; theory-practice relationship; quality in higher education.

\section{INTRODUÇÃO}

O processo formativo, hoje em dia, é tema de constantes pautas e as universidades tem uma maior incumbência na qualidade e satisfação desses sujeitos a serem formados. Segundo Viana, Melz, Santos e Stielera (2013, p. 6) "ao se falar em qualidade da IES a partir da satisfação do alunado, os acadêmicos conducentes estão mais preparados, pois possuem um maior grau de informação e conhecimento sobre a mesma”, podendo com isso formular uma opinião mais consistência embasada nas experiências já vivenciadas dentro da instituição.

Em consonância ao estudo de Kruger, Mazzioni, Resende, Gubiani e Zanin (2013, p. 46), "ao egressar da graduação espera-se que esteja qualificado para assumir as responsabilidades inerentes à profissão, se adapte às mudanças no contexto em que está inserido, com a finalidade de auxiliar as organizações no desempenho de suas atividades".

Uma área de grandes embates acerca da formação profissional é a contabilidade, pois se trata de uma ciência social aplicada e carece dessa proximidade prática, ou até digamos aplicada socialmente, para conseguir ter maior imersão sobre o que se pratica no mercado contábil. Pinto (2018, p. 86) sugere "uma formação profissional pautada numa epistemologia da prática é importante como um espaço de construção do conhecimento e de reflexão das situações reais". Também podendo ser amplamente difundida para aproximar a teoria da prática, consiste na realização de estágios a complementação do ensino e da aprendizagem, em termos de treinamento prático, aperfeiçoamento técnico cultural, científico e de relacionamento humano (Cassundé, Oliveira, Alencar, Rodrigues, \& Rodrigues, 2017; Melz \& Raia, 2011).

Diante dessa contextualização prévia, esse estudo teve a intenção analisar o estágio supervisionado como requisito importante na formação profissional do contador, e a partir e um experimento objetivou-se em comparar os acadêmicos concludentes que estão imersos no mercado de trabalho e os que não estão sobre a importância do estágio supervisionado no curso de ciências contábeis. E questiona-se nesse estudo: Qual é a 
percepção do sujeito concludente sobre o estágio do curso de ciências contábeis, interligado as demandas requeridas pelo mercado de trabalho?

Essa pesquisa justifica-se pela importância da vinculação entre o domínio das normas e princípios que regem, constroem e difundem a ciência contábil ao saber prático dessa formação. Acerca disso, Moreira (2013) reafirma a necessidade do sujeito contábil obter o domínio esperado dos saberes teóricos e práticos, sendo estes indissociados e imprescindíveis em sua formação e assim, seja emancipado com a práxis resultante do processo.

Com a finalidade de melhor apresentar os conteúdos acerca desse estudo, o mesmo foi divido sequencialmente em duas seções teóricas, abordando a importância da satisfação do concludente quanto a sua formação, o processo formativo do acadêmico de contabilidade, com duas subseções a relação da teoria/prática e por fim, o estágio supervisionado e sua importância formativa; depois são apresentado os caminhos metodológicos traçados nessa pesquisa e por conseguinte a análise dos resultados encontrados dando embasamento para relatar os pareceres conclusivos desse estudo.

\section{REFERENCIAL TEÓRICO}

\subsection{A IMPORTÂNCIA DA SATISFAÇÃO DO CONCLUDENTE}

As organizações, no cenário atual, estão cada vez mais adaptando rapidamente para desenvolver uma gestão que atenda as expectativas e necessidades de seus clientes. Esse pré-requisito não se faz diferente em organizações educacionais (Lizote, Verdinelli, Terres, Sauer Camozzato, \& Seemann, 2018), pois responde ao essencial para formação de profissionais qualificados para o exercício da profissão (Carneiro, Rodrigues, França, Almeida, \& Morais, 2017), ou seja, o feedback dos consumidores do serviço.

A universidade é o local adequado para a construção de conhecimento que deve contribuir para provocar transformações na própria sociedade em que está inserida. E com isso, desenvolve um papel importante atualizando, instruindo e capacitando pessoas nas mais variadas áreas, sendo que a evolução da universidade depende da constante 
atualização e aprimoramento das técnicas que perfazem o perfil profissiográfico da formação do cidadão dotado de sustentação científica. Por isso, percebe-se que a Universidade tem de, necessariamente, criar condições para a auto realização do estudante. (Kruger, Mazzioni, Resende, Gubiani, Zanin, \& 2013; Brandalise, Rojo, Kasper, \& Souza, 2013; Oro, Naue, Stürmer, \& Brito, 2010).

Gutiérrez e Camblor (2007) dizem que os alunos satisfeitos com os serviços da IES influenciam positivamente na percepção que a sociedade e os futuros alunos têm a seu respeito, incrementando a demanda (Nascimento, Bernardes, Sousa, \& Lourenço, 2016). Mas avaliar a satisfação é algo complexo, pois responde a própria sobrevivência das instituições afetando-se, caso a qualidade do serviço prestado não for aquele esperado pelo público (Dias, Theóphilo, \& Lopes, 2010; Lizote et al., 2018; Nascimento et al., 2016; Viana et al., 2013).

Não atender a tais expectativas, acredita significativa parte dos gestores de IES no Brasil, implica em menor atração de novos alunos, perda de espaço frente a "concorrência" e, consequentemente, perda de recursos financeiros e lucro (Crubellate, Mendes, \& Junior, 2009). Assim, buscar esse retorno dos acadêmicos ou egressos é uma ferramenta estratégica de gestão, caso isso não ocorra, a consequência é a desvalorização e a evasão, complementando estudos já realizados por autores como Dias et al. (2010) e Nascimento et al. (2013).

Ao avaliar a qualidade da IES, a partir da satisfação do alunado, Brandalise et al. (2013, p. 180) assegura que "a avaliação realizada por egressos ou concludentes pode constituir uma importante referência de qualidade dos serviços das IES, na formação profissional contábil e que os cursos se adequem as perspectivas do mercado, através de preceitos curriculares e pedagógicos".

Assim, a ótica de formação dos acadêmicos de ensino superior está cada vez mais voltada às demandas mercadológicas, retratando dessa forma a influência da intenção das IES na construção de um profissional preparado qualitativamente para atuar e se manter no mercado de trabalho, o que proporciona diversos ganhos para a sociedade como um todo (Lizote et al. 2018). 


\subsection{FORMAÇÃO PROFISSIONAL CONTÁBIL}

Para o curso de ciências contábeis e sua presença prática formativa, o contexto de constantes mudanças é bastante dinâmico, então deve-se preparar o estudante, ajudando-o a desenvolver competências e habilidades, que lhe oferençam segurança para assumir o exercício profissional e capacidade para corresponder às exigências dos usuários da informação contábil (Kruger et al., 2013). Assim, a universidade tem a finalidade de inserir profissionais aptos para o exercício profissional, obtendo retorno quanto à qualidade desses profissionais que vem formando (Moura \& Schimidt, 2016).

Nesse sentido, a elaboração de um novo currículo é ferramenta imprescindível, pois apoiando aos CFC (2015) “o profissional da contabilidade moderno deve ser ágil, competente, antenado e possuir a informação na ponta da língua para ajudar seu cliente a gerir o seu negócio" (p.11). Sendo que essa conjuntura deverá estar em consonância com as Diretrizes Curriculares Nacionais e na sua flexibilização curricular instituída que permite superar os estreitos contornos de currículos mínimos obrigatórios (SANTOS et al., 2014).

A formação do profissional contábil sempre terá como bases essa relação dos conteúdos teóricos e da aplicabilidade deste a perspectiva prática, pois conforme Moreira (2013, p. 60) "o contador deve ser capaz de aplicar os conhecimentos teóricos na prática, em situações reais, obtendo, analisando, interpretando, sintetizando, avaliando e comunicando informações". Na área contábil, o mercado de trabalho, por sua vez, exige profissionais cada vez mais preparados, que detenham conhecimentos necessários para demonstrar o desempenho organizacional, apresentar soluções aos problemas identificados, compreensão sobre práticas de gerenciamento tributário, que visem à redução, à maximização dos lucros e à continuidade da organização (Moreira, 2013).

Propõe-se que o profissional contábil possua um conjunto de instrumentos indispensáveis, que compõem o seu perfil profissiográfico, e este deve estar disposto a manter-se atualizado e aperfeiçoar-se de acordo com as necessidades do mercado, pois só assim conseguirá enfrentar as pressões e desafios constantes (Degenhart, Vogt, \& Biavati, 2014; Brandalise et al. 2013). 


\subsubsection{RELAÇÃO TÉORICO-PRÁTICA}

No processo de formação profissional, vale o destaque acerca da relação teoria e prática dos componentes curriculares da graduação. Para tanto, esse processo é característica de aplicação e imersão na realidade local sobre a sua ciência. Carvalho Junior (2015, p. 94) complementa que "essa dissociação da teoria e da prática faz com que os alunos não enxerguem uma ação efetiva interdisciplinar, devido à falta de ligação entre as disciplinas e as dificuldades geradas pela reaproximação entre elas, resultando em conhecimentos segregados ao longo do tempo". Para isso, a educação, na construção e no desenvolvimento de identidades, deverá transcender o contexto teórico da sala de aula, recomendando a aplicação de estratégias educacionais como aprendizado ativo, aprendizado experiencial, simulações e aprendizado social, diminuindo a distância entre a experiência acadêmica e requisitos da vida real (Oliveira, 2019; Silva, 2019).

Percebe-se que relação teórico-prática é útil a diversos campos do conhecimento permitindo concluir que o estágio, nos currículos, se configura como oportunidade à formação, viabilizando práticas e conciliando saberes e teorias apropriadas a contextos locais (Calazans, Souza, Pequeno, Araújo, \& Lima Júnior, 2019).

\subsubsection{O ESTÁGIO SUPERVISIONADO CONTÁBIL E SUA IMPORTÂNCIA FORMATIVA}

O estágio supervisionado é parte dessa formação profissiográfica do contador. Pois o devido profissional deve ater-se a um perfil adequado e apto com formação críticoreflexiva e, principalmente, adaptação ao sistema em que se vive. Para Melz e Raia (2011, p. 115) "o contador tem a missão de desenvolver, analisar e implantar sistemas de informação contábil e de controle gerencial e necessita de conhecimento técnico e científico". Tal profissional tem inúmeros locais de trabalho, e várias áreas de aperfeiçoamento, mas a área em que há maior concentração na atividade contábil é na atuação como empresário da contabilidade que prestam serviços para outras empresas e para os bons resultados necessita ter competência para analisar de forma critica as empresas no seu aspecto organizacional (Melz \& Raia, 2011). 
Entendido o perfil de profissional que se busca formar, representa-se nesse discurso a forte presença de trechos práticos e competências empíricas ao cenário mercadológico, e assim, se relaciona com o estágio, pois para a Lei 11.788 de 2008 o estágio é conceituado como "ato educativo escolar supervisionado, desenvolvido no ambiente de trabalho, que visa à preparação para o trabalho produtivo de educandos" (Brasil, 2008, p. 1) resultante numa aplicação prática dos conhecimentos teóricos aprendidos durante o curso, vislumbrando preparar, profissionalmente, o aluno (Cassundé et al., 2017).

O estágio é componente de responsabilidade da Instituição de Ensino, determinante da formação profissional na qual se realiza por atividades de aprendizagem social, profissional e cultural (UNB, 2010b). Nesse sentido, torna-se indispensável o seu uso, pois em cursos como ciências contábeis, o conteúdo é aplicado e o acadêmico participa e interage com o ambiente diário das organizações (Wittmann; Trevisan, 2002). Mediante a essa situação, a perspectiva de formar um contador para possuir o conhecimento plural não é uma tarefa simples, pois os conteúdos e conhecimentos são sempre inconclusivos devido à educação continuada, e de atualizações relacionais das teorias com a prática profissional. Com isso, necessita-se repensar o modelo de formação visando processos mais críticos e que priorizem ações e conhecimento na articulação entre teoria e prática da contabilidade (Laffin \& Castro, 2015).

E nessa perspectiva, o estágio torna-se um momento imprescindível para formação do aluno, pois é um período de aprendizado e de construção da relação entre a teoria, que foi fundamentada nos primeiros anos de curso e que a prática irá desenvolver (Silva, 2015).

\section{METODOLOGIA}

\subsection{DELINEAMENTO DA PESQUISA}

A metodologia adotada nesse estudo teve inspiração qualitativa, uma vez que a pesquisa se fundamenta em questionamentos relacionados à qualidade do estágio supervisionado no ensino superior frente a inserção mercadológica de profissionais da contabilidade (Martins \& Theóphilo, 2007). A estratégia para condução da investigação foi amparada na aplicação de um experimento (Fleury \& Werlang, 2017) com alunos 
concludentes do curso de ciências contábeis de uma Instituição de Ensino Superior - IES, a partir da separação aleatória do grupo de tratamento (percepção a ser testada) e do grupo de controle (grupo não afetado).

\subsection{SUJEITOS, INSTRUMENTO E TÉCNICA DE COLETA DOS DADOS}

Com o intuito de identificar as percepções dos acadêmicos do curso de ciências contábeis sobre a satisfação com o estágio supervisionado, realizou-se a aplicação de questionários estruturados com os alunos concludentes do curso em uma IES. Os questionários foram constituídos por uma série de perguntas ordenadas para a coleta de dados complexos (Carvalho, Valença, Santos, Correia, \& Lima, 2017), visando alcançar uma maior uniformidade nas respostas acadêmicas sobre o estágio e o curso (Oliveira, Oliveira, Morais, Silva, \& Silva, 2017).

O critério para seleção dos sujeitos fundamentou-se na escolha de acadêmicos de uma mesma IES que tivessem estudado com o mesmo currículo (Lima \& Silva, 2017), considerando a possibilidade de terem havido alterações curriculares (disciplinas, atividades de extensão e pesquisa etc.) durante o andamento do curso. Outro parâmetro é pautado na escolha de acadêmicos enquadrados no sétimo ou oitavo período, ou seja, estar cursando, ou já ter cursado, o estágio supervisionado, considerados com uma maior capacidade para avaliação institucional. A IES foi selecionada por questões de acessibilidade do pesquisador (Collado, Lucio, \& Sampieri, 2006), após percorrer por três instituições apresentando a pretensão da pesquisa.

A partir dos critérios indicados, foram selecionados 27 discentes cursando o último ou penúltimo período de ciências contábeis da IES escolhida. Dado importante da pesquisa foi que destes, 17 (dezessete) nunca trabalharam com contabilidade e os demais (dez) já tiveram atuação prática dessa ciência fora da academia. Com isso, houve uma equiparação percentual dos dois grupos, para não haver maior peso analítico para um grupo ou outro. Ou seja, 5 (cinco) discentes sem atuação prática para cada grupo investigado.

Para a construção do instrumento, foram formulados 14 questionamentos através da escala Likert, em maior parte, de cinco pontos. Esses questionamentos foram ordenados numa sequência linear, abordando a capacitação e a satisfação com o curso e por fim, com 
o estágio supervisionado. Os dados foram coletados através de uma pesquisa Survey (Pinsonneault \& Kraemer, 1993) por meio aplicação do questionário estruturado de maneira presencial, em sala de aula com o corpo discente concludente da IES selecionada, no dia 01 de novembro de 2019. Para o preenchimento dos questionários pelos entrevistados, foram gastos, em média, 30 minutos.

A tarefa consistiu em uma atividade objetiva com perguntas precisas sobre a capacidade dos investigados em compreender as demandas práticas da contabilidade. A propositura dessa obra pautou-se em compreender se existiam déficits curriculares na prática contábil na Universidade (estágio) em relação à realidade mercadológica e se esses déficits repercutem em menor capacidade e/ou facilidade para a inserção no mercado de trabalho.

Por tratar-se de uma pesquisa experimental, foram divididos dois grupos: os que já trabalham com contabilidade fora da academia (grupo experimental) e os que só veem a contabilidade através da graduação (grupo de controle). A divisão de grupos experimental e de controle se sucedeu através da primeira questão do questionário que pergunta se os mesmos trabalham com contabilidade ou não, e depois foi estruturado estatisticamente os respondentes e qual grupo é maior ou menor para a referida amostra. As variáveis para análise do experimento foram a inserção mercadológica, formação contábil e satisfação acadêmica gradual (variáveis dependentes) e a prática contábil (variável independente).

\subsection{TRATAMENTO DOS DADOS}

O método de tratamento dos dados envolveu a separação dos grupos experimentais e de controle e, seguidamente, percorreu a análise das respostas com base em escalas percentuais, devido à falta de igualdade na quantidade de sujeitos em cada grupo. Na sequência, realizou-se uma análise das variáveis e fatores importantes para cada grupo, visando "identificar fatores ou dimensões latentes que refletem o que as variáveis têm em comum" (Hair, Black, Babin, Anderson, \& Tatham, 2009, p.112). Sendo assim, buscou-se identificar as dimensões ou construtos latentes representados nas variáveis originais (Hair et al., 2009). 
A análise dos dados seguiu a proposição de cada questionamento e suas variáveis presentes na elaboração do experimento. Através da separação dos grupos experimentais e de controle, foi possível visualizar a distinção de opiniões dos dois grupos e quais dados são mais relevantes para estes grupos. A observação também foi relevante para a pesquisa, pois muitos outros fatores foram encontrados na sua execução, conforme se debate na seção dos resultados.

Os questionários foram avaliados percentualmente pela sua semelhança ou variação das opiniões dos grupos experimentais e de controle. A operacionalização dos dados foi realizada com apoio de operações matemáticas e estatísticas do software Excel®. Através da única questão discursiva foi possível encontrar outras lacunas existentes nas temáticas abordadas no curso de contabilidade e em especificidade, no estágio supervisionado. A resposta à essa questão foi tratada qualitativamente.

\section{RESULTADOS}

Como evidências da pesquisa constatou-se uma similaridade nos dados relativos à variável satisfação, alcançando um elevado grau de aceitação pelos grupos experimentais e de controle com o curso e o estágio.

Considerando as evidências da pesquisa, a variável de inserção mercadológica, talvez seja a que mais possibilitou o distanciamento dos grupos experimentais e de controle. Pois quando se questionava a variável dependente da inserção com a independente da prática a luz da capacitação, houve um distanciamento dos grupos. O grupo experimental teve basicamente $70 \%$ de respostas afirmando a incapacidade de execução do trabalho contábil, validando a hipótese de déficits na formação acadêmica devido à ausência da variável independente (prática contábil). Já o grupo de controle teve $60 \%$ das respostas afirmando a capacidade da execução do trabalho contábil, mostrando que a presença da variável independente (prática contábil) faz com que as variáveis dependentes repercutam em resultados positivos.

Frente à inserção mercadológica, questionou-se a percepção dos grupos sobre o mercado de trabalho. O grupo experimental tem uma percepção de $35 \%$ com poucas 
possibilidades de inserção mercadológica, já o grupo controle obteve apenas $20 \%$ de poucas possibilidades de inserção mercadológica devido à prática contábil (variável independente).

A variável de satisfação dos estágios traz o embate da prática contábil como recurso interligado a formação profissional. O grupo experimental obteve um percentual de $29 \%$ de insatisfação com os estágios e de $18 \%$ com a correlação dos conteúdos com o que se anseia de prática fora da academia. Já os grupos de controle não mostraram insatisfação com o conteúdo trazido e com a sua correlação com a prática mercadológica. Esse dado afirma que a prática contábil faz com que a formação profissional tenha dados mais positivos na percepção dos alunos, e os que não têm a prática mercadológica, não completam sua satisfação com apenas a prática acadêmica.

A variável dependente da formação profissional trouxe um questionamento sobre o currículo do curso (ritos de controle) e se este atende as necessidades dos sujeitos. Nesse caso, a variável independente da prática contábil não disseminou distanciamentos e ambos os grupos afirmaram que a variável formação profissional é parcialmente atendida mediante aos ritos de controle dessa pesquisa.

A questão discursiva sintetizou-se na variável da inserção mercadológica, fazendo relação aos ao mercado e suas demandas, para que as IES se atentem a esse fator relevante que é a devida estruturação de um currículo para a sua regionalidade. Os grupos experimentais e de controle tiveram escolhas de áreas distintas. Para o grupo experimental a melhor área para a inserção mercadológica é a da contabilidade pública com 41,18\%, seguido da contabilidade tributária (17,78\%), fiscal (11,76\%), consultoria (11,76\%), e comercial $(11,76 \%)$. E para o grupo de controle a predominância foi para a contabilidade comercial, fiscal e controladoria com $30 \%$ cada uma; e a área publica obteve apenas $10 \%$ das respostas.

O que pode se extrair com esse dado é que os grupos experimentais sentem-se carentes de conteúdos para áreas públicas, devido a constante falta de prática nessa área, e ao grupo de controle afirma-se mais ainda a variável independente que segmentam as três áreas mais fortes no que condiz apática contábil para a região, devido a forte demanda de trabalhos para empresas privadas. Esse dado afirma que ver o currículo como parte de um local, responde a perspectiva de formação qualificada do discente, com base na qual ele 
possa entender as práticas organizacionais vinculadas às teorias por meio da aplicabilidade na região em que ele se insere, dessa forma, promovendo um aprendizado significativo e, em última instância, também, permitindo o próprio desenvolvimento regional (Lima \& Silva, 2017).

Já quando se questiona sobre o currículo do curso, há um breve distanciamento dos dados, pois $23 \%$ do grupo experimental não questionam a reformulação do currículo, e no grupo de controle são $10 \%$ que não se sentem incomodados com o currículo. Justificativa essa se dá devido a variável independente (prática contábil) que, para o grupo experimental é inutilizada e faz com que parte desse grupo não tenha uma visão ampla sobre as demandas mercadológicas dessa ciência, descompassando as construções teórico-acadêmicas com o que se vê por práxis contábil do mercado.

Partindo das análises realizadas foi possível observar os aspectos relativos a cada grupo de questionamentos propostos.

Os dois primeiros questionamentos tencionaram-se a verificar o nível de identidade dos alunos concludentes com o curso de ciências contábeis, bem como a experiência destes com o mercado de trabalho. Para essa situação identificou que apenas dez alunos têm experiência com o mercado de trabalho, sendo possível fazer uma distinção entre o grupo experimental e o grupo de controle. De acordo com os resultados foi possível também perceber a existência de um caráter de identidade preponderante dos alunos concludentes com o curso de ciências contábeis a partir de uma similaridade nas respostas (76,47\% grupo experimental e $90 \%$ grupo de controle), o que favorece um interesse pela formação profissional adequada às demandas mercadológicas.

Os três questionários sequenciados buscaram analisar a percepção dos alunos concludentes quanto à adequação dos determinantes curriculares aos temas relevantes das ciências contábeis. E os resultados desses questionamentos trouxeram uma contradição entre os respondentes sobre a adequação dos determinantes curriculares aos temas relevantes, uma vez que a maioria (82,35\% grupo experimental e $70 \%$ grupo de controle) não observa a ausência de temas relevantes sobre a contabilidade tratados no estágio, muito embora boa parte dos respondentes (70,59\% grupo experimental e 60\% grupo de controle) afirma que a IES não atende, curricularmente, ao melhor ramo de trabalho na região. Outra observação é a de que não houve respostas para a pergunta quatro: Como ferramenta de 
inserção mercadológica, qual seria o melhor ramo para se trabalhar na sua região? Apesar da pergunta cinco, relacionada a esta pergunta, ter sido plenamente respondida.

Juntos as duas questões seguintes, objetivou-se nesse tópico identificar o nível de satisfação dos alunos concludentes com os conhecimentos práticos adquiridos e sua correlação com as experiências vividas na prática. E nesse tópico, os resultados relataram que os alunos concludentes, de maneira geral, demonstram satisfação com os conhecimentos práticos obtidos no estágio profissional (70,59\% grupo experimental e $90 \%$ grupo de controle) e com a correlação dos conteúdos trazidos no estágio com as experiências vivenciadas na prática (64,70\% grupo experimental e 70\% grupo de controle).

A partir da oitava questão até a última tencionou-se com esse estudo a certificar se o currículo da IES de vínculo dos alunos concludentes gera segurança profissional e possibilitam a formação de acordo com as demandas do mercado trabalho. E com o último tópico foi comprovado que nas respostas apresentadas subsiste a compreensão dos alunos concludentes quanto ao descompasso da prática contábil acadêmica com a prática contábil mercadológica (82,35\% grupo experimental e $90 \%$ grupo de controle).

Essa afirmativa converge com a perspectiva dos alunos quanto à segurança para se trabalhar com a contabilidade, em caso de formação recente para o grupo experimental, $58,82 \%$ se sentem pouco capacitados ou incapacitados, apesar de não convergir com a percepção do grupo de controle, onde $60 \%$ se sentem capacitados. Os alunos evidenciam, ainda, que o currículo de ciências contábeis da IES atende parcialmente as suas necessidades de formação (70,59\% grupo experimental e 70\% grupo de controle).

Outra observação é a pequena distância quanto à expectativa em relação à entrada no mercado de trabalho, onde 70,59\% entre os respondentes do grupo experimental anseiam estar empregados no máximo em um ano após formação e 70\% do grupo de controle almeja estar empregado antes do término do curso. $\mathrm{Na}$ avaliação dos alunos concludentes sobre o mercado de trabalho boa parte (41,18\% grupo experimental e $50 \%$ grupo de controle) enxerga boas possibilidades de inserção mercadológica. Por fim, a maioria dos alunos concludentes (76,47\% grupo experimental e $90 \%$ grupo de controle) afirma que o currículo de ciências contábeis precisa passar por uma atualização de conteúdos.

Nessa perspectiva, a segurança na sua formação acadêmica (VD) tem uma relação positiva com aqueles que tiveram acesso à prática contábil (VI) e os demais, sentem-se 
inseguros ou pouco capacitados para conseguirem validade para a inserção mercadológica (VD). Assim, 60\% do grupo de controle enxerga boa capacitação sobre a sua formação contábil, e 52,94\% de pouca capacitação. Comprovando o teste, afirmando que acadêmicos com o uso das práticas contábeis no ambiente mercadológico tem maior certeza sobre a sua capacidade quanto acadêmico.

Portanto, retrata-se a partir desse estudo a comprovação de uma relação, não tão forte, mas presente na formação dos contadores acerca do cenário prático como recurso capacitdor e satisfatório para a inserção mercadológica. Ou seja, nessa análise entre práticas acadêmicas e práticas mercadológicas, visualizou-se que grande parte dos sujeitos experimentais (apenas com uso da prática acadêmica) são mais insatisfeitos ou até questionadores da sua devida capacidade, e isso, todavia não deveria existir numa graduação que forma os sujeitos para contribuírem socialmente com as demandas do ambiente em que se insere.

Esse impasse se complementa por Silva (2015) que discorre que as disciplinas do curso de ciências contábeis devem atender exigências da Organização Mundial do Comércio (OMC), que busca formar profissionais adequados ao mercado. Assim, não seguindo o que as bases diretivas da OMC entendem sobre a formação profissiográfica.

À luz dos dados coletados é estabelecida uma proposta de inovação para a composição do currículo do curso de ciências contábeis para a IES em análise de modo que se recomponham alguns preceitos teórico-empíricos visando à formação desses sujeitos a um pragmatismo mais direcionado a prática contábil e a sua presença como recurso contribuinte para o desenvolvimento local e regional.

Os grupos experimental e de controle culminaram a partir da questão discursiva possíveis reajustes na sua composição curricular, lembrando que não se objetivou nesse estudo de alterar o currículo como um todo, e desrespeitar as propostas as Diretrizes Curriculares Nacionais e ao currículo mínimo proposto juntos as federações a cerca do curso de contabilidade. Os respondentes de controle deram ênfase nas demandas regionais da faculdade que foi aplicada a pesquisa, que são: contabilidade comercial, fiscal e controladoria. Os respondentes do grupo experimental deram ênfase nas outras áreas da contabilidade, como: contabilidade pública, contabilidade tributária e entre outras.

Para se lançar uma proposta de reajuste não se tentou dar maior ênfase no grupo de 
controle, acima do experimental, mas sim criar uma ferramenta complementar ajustada a região demandada para a contabilidade.

Para o estágio a proposta é de tentar segmentar os dois estágios supervisionados, conforme dados do projeto politico pedagógico da IES, um na área escritural com desmembrações para a contabilidade tributária, fiscal e comercial; o segundo dando a ênfase na controladoria que cria do sujeito esse posicionamento critico e reflexivo (Silva, 2015).

À luz do curso como um todo a principal proposta de inovação a ser dada é de tentar fazer essa intersecção de teoria e prática a partir das disciplinas, sendo apenas uma proposta de metodologia ativa, com casos empíricos corriqueiros as demandas regionais da contabilidade. Observa-se que essa intersecção não tem nenhuma intenção de alterar o cronograma conteudista de cada disciplina, mas sim de tentar tratar esses conteúdos de forma que o sujeito seja formado com maior desenvolvimento empírico a demanda local.

\section{CONCLUSÕES}

A pesquisa buscou verificar se os determinantes curriculares que compõem o estágio do curso de Ciências Contábeis possibilitam a formação de profissionais em consonância com as demandas requeridas pelo mercado de trabalho. Para tanto, a hipótese estabelecida foi a de que a prática contábil sem uma contextualização com a realidade mercadológica proporciona um déficit na formação profissional, repercutindo em menor capacidade e/ou facilidade para a inserção no mercado de trabalho.

Concluiu-se que, a partir das análises, a hipótese estabelecida deve ser recusada, considerando a contraposição entre as respostas dos alunos concludentes. É notório que boa parte dos alunos afirma que a IES não atende, curricularmente, ao melhor ramo de trabalho na região. Além disso, há uma compreensão quanto ao descompasso da prática contábil acadêmica com a prática contábil mercadológica, bem como um entendimento de que o currículo de ciências contábeis precisa passar por uma atualização de conteúdos.

No entanto, a maioria dos alunos concludentes não observa a ausência de temas relevantes sobre a contabilidade tratados no estágio, assim como demonstram satisfação 
com os conhecimentos práticos obtidos no estágio profissional e com a correlação dos conteúdos trazidos no estágio com as experiências vivenciadas na prática. Outrossim, a maioria dos alunos evidencia que o currículo de ciências contábeis da IES atende parcialmente as suas necessidades de formação.

Não obstante, ao considerar a prevalência da satisfação com o estágio profissional, uma sugestão para a base curricular do curso de Ciências Contábeis seria a ampliação do investimento no estágio como forma de capacitar os universitários para o mercado de trabalho, colocá-los durante um período dentro de empresas real para conhecerem na prática a profissão a qual estão se formando. Outra perspectiva seria uma maior aproximação dos alunos concludentes com as oportunidades de mercado na região de proximidade dos mesmos, uma vez que os alunos demonstraram restrito conhecimento sobre os ramos de trabalho regionais.

Como limitações do estudo, pode-se destacar a amostra, pois possui características bem definidas que apontam as opiniões de alunos concludentes de uma instituição, envoltos pelo receio de sofrerem algum tipo de retaliação acerca da repercussão das suas respostas frente à grade curricular da IES que eles integram. Além disso, a possibilidade de não assimilação do objetivo das perguntas e a integração entre elas pode ter comprometido a assertividade nas respostas pelos alunos.

Por fim, uma das sugestões para pesquisas futuras é a aplicação do mesmo estudo para outras amostras mais abrangentes de alunos concludentes ou com egressos do curso de ciências contábeis para posterior comparação e confronto de resultados para verificar se há uma convergência na compreensão das determinantes curriculares que de fato tem aplicabilidade com a vivência prática dos contadores.

\section{REFERÊNCIAS}

Araújo, V. D. S., Santos, D. G. D., Cavalcante, P. R. N., \& Barbosa, E. T. (2015).

Academic formation in accounting sciences and its relationship with the labor market: the perception of the accounting sciences's students of a higher education federal institution. Revista de Gestão, Finanças e Contabilidade, 5(1), 123-139.

Brandalise, L. T.; Rojo, C. A.; Kasper, D.; Souza, A. F. (2013) O papel social da universidade no preparo profissional: uma pesquisa junto aos egressos de administração da Unioeste - Cascavel. Revista GUAL, Florianópolis, v. 6, n. 1, p. 176-196. 
Brasil. Lei $\mathrm{n}^{\circ} 11.788$, de 25 de setembro de 2008. Dispõe sobre o estágio de estudantes; altera a redação do art. 428 da Consolidação das Leis do Trabalho (CLT). Diário Oficial da União, Brasília, DF, 26 set. 2008.

Cassundé, F. R. S. A., Oliveira, M. V. S., Alencar, M. T. C., Rodrigues, N. F. M., \& Rodrigues, E. E. D. (2017). [Re]Pensando o Estágio na Formação Profissional dos Estudantes de Administração: Um Estudo sobre a Produção Científica Brasileira na Área. Administração: Ensino e Pesquisa, 18(3), 594-623.

Calazans, D. L. M., Souza, W. J., Pequeno, N. P. F., Araújo, F. R., \& Lima Júnior, V. (2019). Integrando a Extensão Universitária ao Ensino e à Pesquisa em Administração: Sistematização de Experiência Junto a Indígenas à Luz dos Objetivos do Desenvolvimento Sustentável . Administração: Ensino e Pesquisa, 20(3), 1-29.

Carneiro, J. D., Rodrigues, A. T. L., Silva, A. C. R., França, J. A., Almeida, J. E. F. \& Morais, M. L. S. (2017). Matriz curricular para cursos de ciências contábeis. Fundação Brasileira de Contabilidade, Brasília.

Carvalho, C. V. D.; Valença, T. D. C., Santos, J. A., Correia, I. F. \& Lima, P. V. (2017). Aplicação de questionários online na pesquisa científica com idosos: relato de experiência. Trabalho apresentado V Congresso Internacional de Envelhecimento Humano, Editora Realize, Maceió.

Carvalho Junior, L. E. (2015). Estereótipos do profissional da Contabilidade na percepção de estudantes de cursos preparatórios para ingresso no ensino superior. (Dissertação de Mestrado). Programa de Pós-Graduação em Ciências Contábeis e Atuariais. Universidade Federal de Minas Gerais, Belo Horizonte.

Degenhart, L.; Vogt, M. \& Biavati, V. T. (2014) A Efetivação do Perfil do Egresso das Diretrizes Curriculares Nacionais para o Curso de Ciências Contábeis na Percepção dos Acadêmicos. Trabalho apresentado no V Congresso UFSC de Controladoria e Finanças e Iniciação Cientifica em Contabilidade; Santa Catarina.

Dias, E. C. Theóphilo, C. R. \& Lopes, M. A. (2010). Evasão no ensino superior: estudo dos fatores causadores da evasão no curso de Ciências Contábeis da Universidade Estadual de Montes Claros - Unimontes-MG. Trabalho apresentado no Congresso USP De Iniciação Científica Em Contabilidade, São Paulo.

Fleury, M. T. L., \& da Costa Werlang, S. R. (2017). Pesquisa aplicada: conceitos e abordagens. Anuário de Pesquisa GVPesquisa..

Gutiérrez, S. A.; Camblor, M. P. (2007). Principales factores de satisfacción entre los estudiantes universitarios. La unidad académica multidisciplinaria de agronomía y ciencias de la UAT. Revista Internacional de Ciencias Sociales y Humanidades, 18(1), 163-192.

Hair Jr., J.F.; Black, W.C.; Babin, B.J.; Anderson, R.E. \& Tatham, R.L. (2009) Análise 
multivariada de dados. 6. ed. Porto Alegre, Bookman.

Kruger, S. D., Mazzioni, S., Resende, A., Gubiani, C. A., \& Zanin, A. (2013). O perfil desejado do egresso dos cursos de ciências contábeis das universidades de Santa Catarina. Revista Catarinense da Ciência Contábil, 12(34), 40-52.

Laffin, M. \& Castro, C. C. T. (2015) Professional practice perpectives of the UFSC accounting sciences students. Revista de Gestão, Finanças e Contabilidade, v. 5, p. 58-76.

Lima, T. B., \& Silva, A. B. (2017). O Ambiente Estrutural e Institucional do Ensino de Administração na Região Nordeste do Brasil. Administração: Ensino e Pesquisa, 18(2), 231-269.

Lizote, S. A., Verdinelli, M. A., Terres, J. C., Sauer Camozzato, E., \& Seemann, J. dos S. (2018). Satisfação dos alunos com o curso de ciências contábeis: uma análise em diferentes instituições de ensino superior. Revista Ambiente Contábil - Universidade Federal Do Rio Grande Do Norte, 10(1), 293-307.

Martins, G. de A., \& Theóphilo, C. R. (2009). Metodologia da investigação científica para ciências sociais aplicadas. São Paulo: Atlas.

Moreira, J. A. P. (2013) Entre a teoria, a prática e a tecnologia: relação entre o saber teórico e o saber prático no contexto da formação contábil. Dissertação, Mestrado . Programa de Pós-Graduação em Gestão em Organizações Aprendentes, Departamento de Educação. Universidade Federal da Paraíba, João Pessoa.

Moura, J. E. ; Schmidt, C. M. (2016) Gestão de egressos no ensino superior: construção teórica e o caso do curso de graduação em secretariado executivo da Unioeste--PR. Revista Expectativa, v. 15, n. 15.

Nascimento, J. C. H. B.; Bernardes, J. R.; Sousa, W. D.; \& Lourenço, R. N. (2016). Avaliação Institucional: Aplicação da Teoria da Resposta ao Item Para Avaliação Discente em Ciências Contábeis. Future Studies Research Jornal. São Paulo, v.8, n.2, p. 122-148.

Oliveira, J. C. P; Oliveira, A. L., Morais, F. A. M., Silva, G. M.; \& Silva, C. N. M. (2017). $O$ questionário, o formulário e a entrevista como instrumentos de coleta de dados: vantagens e desvantagens do seu uso na pesquisa de campo em ciências humanas. Trabalho apresentado no III Congresso Nacional De Educação - CONEDU. Natal.

Oro, I. M., Naue, J., Stürmer, A. L., \& Brito, F. (2010). Egressos em Ciências Contábeis: análise do desenvolvimento profissional sob o enfoque da Teoria do Capital Humano. Revista Universo Contábil, 6(4), 35-49.

Pinsonneault, A.; Kraemer, K. (1993) Survey research methodology in management information systems: an assessment. Journal Of Management Information Systems, v. 10, n. 2, p. $75-105$. 
Raia, F. S., \& Melz, L. J. (2011). Percepção dos discentes e docentes sobre estágio supervisionado no curso de ciências contábeis da UNEMAT - campus de Tangará da Serra. Revista Contemporânea de Contabilidade, 8(16), 111-136.

Reis, A. O., Sediyama, G. A. S., Moreira, V. S., \& Moreira, C. C. (2015). Perfil do profissional contábil: habilidades, competências e imagem simbólica. Revista Contemporânea de Contabilidade, 12(25), 95-116.

Sampieri, R.H.; Collado, C.F. \& Lucio, P.B. (2006). Metodologia de pesquisa. 3.ed. São Paulo: McGraw-Hill.

Silva, S. C. (2015). Currículos dos cursos de Contabilidade: discussão em uma perspectiva educacional moderna e pós-moderna. Enfoque Reflexão Contábil, 34(2), 15-36.

Silva, E. B. (2019) Análise comparativa das instituições privadas de ensino: estudo sobre as matrizes curriculares dos cursos de ciências contábeis do estado de São Paulo com maior aprovação no exame de suficiência do conselho federal de contabilidade (Dissertação de Mestrado). Programa de Pós-Graduação em Ciências Contábeis e Atuariais. Pontifícia Universidade Católica de São Paulo, São Paulo.

Viana, L. P.; Melz, L. J.; Santos J. S. C.; E Stielera, E. C. (2013) Atuação do egresso do curso de ciências contábeis da UNEMAT - Campus de Tangará da Serra no mercado de trabalho. Revista UNEMAT de Contabilidade, Santa Catarina. v. 2, n. 3 Jan./Jun.

Wittman, M. L.; Trevisan, M. (2002). Estágios extracurriculares e a formação de administradores. Trabalho apresentado no XVI Encontro Da Associação Nacional Dos Programas De Pós-Graduação Em Administração (ENANPAD); Rio de Janeiro. 